\title{
Decomposition routes and strain evolution in arc deposited TiZrAIN coatings
}

Lina Rogström, Mats P. J ohansson, Robert Pilemalm, Naureen Ghafoor, L. J . S. J ohnson, N. Schell and Magnus Odén

The self-archived postprint version of this journal article is available at Linköping University Institutional Repository (DiVA):

http:// urn.kb.se/ resolve?urn=urn:nbn:se:liu:diva- 154526

N.B.: When citing this work, cite the original publication.

Rogström, L., J ohansson, M. P., Pilemalm, R., Ghafoor, N., J ohnson, L. J. S., Schell, N., Odén, M., (2019), Decomposition routes and strain evolution in arc deposited TiZrAlN coatings, J ournal of Alloys and Compounds, 779, 261-269. https:/ / doi.org/ 10.1016/j.jallcom.2018.11.039

Original publication available at:

https:// doi.org/ 10.1016/j.jallcom.2018.11.039

Copyright: Elsevier

http:// www.elsevier.com/

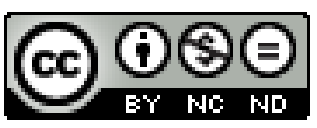




\title{
Decomposition routes and strain evolution in arc deposited TiZrAIN coatings
}

L. Rogström ${ }^{1 *}$, M.P. Johansson Jõesaar ${ }^{2}$, R. Pilemalm ${ }^{1}$, N. Ghafoor ${ }^{3}$, L.J.S. Johnson ${ }^{4}$, N. Schell ${ }^{5}$, and M. Odén ${ }^{1}$

${ }^{1}$ Nanostructured Materials, Department of Physics, Chemistry and Biology (IFM), Linköping University, SE-581 83 Linköping, Sweden

${ }^{2}$ Seco Tools AB, SE-737 82 Fagersta, Sweden

${ }^{3}$ Thin Film Physics, Department of Physics, Chemistry and Biology (IFM), Linköping University, SE-581 83 Linköping, Sweden

${ }^{4}$ Sandvik Coromant, SE-126 80 Stockholm, Sweden

${ }^{5}$ Helmholtz-Zentrum Geesthacht, Max-Planck-Str. 1, D-21502 Geesthacht, Germany

* Corresponding author, lina.rogstrom@liu.se

\begin{abstract}
Phase, microstructure, and strain evolution during annealing of arc deposited TiZrAIN coatings are studied using in situ $x$-ray scattering and ex situ transmission electron microscopy. We find that the decomposition route changes from nucleation and growth of wurtzite AIN to spinodal decomposition when the $\mathrm{Zr}$-content is decreased and the Al-content increases. Decomposition of $\operatorname{Ti}_{0.31} \mathrm{Zr}_{0.24} \mathrm{Al}_{0.45} \mathrm{~N}$ results in homogeneously distributed wurtzite AIN grains in a cubic, dislocation-dense matrix of TiZrN consisting of domains of different chemical composition. The combination of high dislocation density, variation of chemical composition within the cubic grains, and evenly distributed wurtzite AIN grains results in high compressive strains, $-1.1 \%$, which are retained after $3 \mathrm{~h}$ at $1100{ }^{\circ} \mathrm{C}$. In coatings with higher $\mathrm{Zr}$-content, the strains relax during annealing above $900{ }^{\circ} \mathrm{C}$ due to grain growth and defect annihilation.
\end{abstract}

Keywords: Ti-Zr-Al-N; Hard coatings; Thermal stability; Strain evolution 


\section{Introduction}

The complexity of wear resistant coatings used to sustain the harsh conditions of high-speed machining is steadily increasing. Such complexity enhancement is for example seen when TiAIN is used as a starting point and more alloying elements are added [1] and when nanostructured materials such as multilayers include TiAIN [2]. TiAIN exhibits age hardening related to the formation of a microstructure caused by spinodal decomposition consisting of isostructural, coherent, and nm-sized Al-rich and Tirich domains [3, 4]. Adding a fourth element to TiAIN drastically increases the complexity of the decomposition process and offers a way to tune the decomposition, the associated microstructure evolution and in extent, control the evolution of mechanical properties.

Several studies on for example phase stability, oxidation resistance, and mechanical properties reveal improved properties when alloying TiAIN with $\mathrm{Cr}$, $\mathrm{Zr}$ or $\mathrm{Nb}$ of both as-deposited and heat treated samples [5-11]. In Cr-alloyed TiAIN coatings, the complexity of the quaternary alloys is illustrated by two competing mechanisms of decomposition, spinodal decomposition and nucleation and growth of W-AIN, controlled by the chemical composition of the material [12]. The varying microstructure that evolves during heat treatment due to different decomposition routes also affect the thermal stability of the formed CrAIN domains [13]. ZrAIN is a compound with a larger miscibility gap compared to TiAIN $[14,15]$ that frequently causes phase separation already during growth [16-20]. Quaternary TiZrAIN alloys can be synthesized with varying structures depending on the chemical composition [21] and the $\mathrm{Zr}$ alloying changes the high temperature properties compared to TiAIN [6, 22]. The complexity of quaternary systems requires input from theoretical studies in order to predict their behavior. Such data is becoming more available and detailed as the computing power is improved. Theoretical studies can for example predict phase stability and decomposition routes $[1,15]$, elastic properties $[23,24]$ and interface structures [25]. To predict the material behavior at elevated temperature, the knowledge on for example phase stability and elasticity needs to be linked to the evolution of strains and stresses in the coating, which are important aspects influencing how the mechanical properties evolve. In TiAIN coatings, the strain evolution during decomposition is mainly affected by the formation of W-AIN [26] since the larger molar volume of $\mathrm{W}$-AIN compared to the cubic phases results in large compressive strains in the cubic phase. For quaternary Ti(X)AIN-alloys ( $\mathrm{X}$ is a transition metal), the situation is more complex where, in addition to w-AIN, several cubic phases also might form during decomposition [5] and the evolving microstructure is highly dependent on chemical composition [13].

Here, we use the TiZrAIN system to study the effects of phase stability and decomposition route on the strain evolution. We have previously observed that the decomposition route for c-TiZrAIN coatings is highly dependent on the Zr-content [27]. Three c-TiZrAIN coatings with different chemical 
composition were grown by cathodic arc evaporation, selected to have different phase stability according to theoretical predictions. The phase stability and strain evolution during annealing were studied by in situ wide-angle scattering experiments using high energy x-rays. Two decomposition mechanisms are observed, nucleation and growth of w-AIN mainly at column boundaries and spinodal decomposition of the c-TiZrAIN phase. For coatings with a high driving force for spinodal decomposition, this mechanism dominates resulting in formation of cubic domains enriched in either $\mathrm{Zr}$ or Ti and/or Al. In the coating with highest Al-content studied here $\left(\mathrm{Ti}_{0.31} \mathrm{Zr}_{0.24} \mathrm{Al}_{0.45} \mathrm{~N}\right)$, a dislocationdense structure forms subsequent to spinodal decomposition, resulting in a highly strained, cubic phase after annealing at $1100{ }^{\circ} \mathrm{C}$. For coatings with lower Al-content $\left(\mathrm{Ti}_{0.21} \mathrm{Zr}_{0.48} \mathrm{Al}_{0.31} \mathrm{~N}\right.$ and $\mathrm{Ti}_{0.13} \mathrm{Zr}_{0.69} \mathrm{Al}_{0.18} \mathrm{~N}$ ), annealing above $900{ }^{\circ} \mathrm{C}$ results in strain relaxation related to grain growth. In summary, the results reveal that the decomposition route determines both the evolving microstructure and the strain state of the coatings, thus in extension also the mechanical properties. The theoretical predictions of the phase stability and the decomposition routes match the experimental results well and are essential to identify coatings with the right chemical composition for an optimized high temperature behavior.

\section{Experimental details}

TiZrAIN coatings were grown on polished WC-Co substrates (12 wt.\% Co, ISO SNUN120408) using an Oerlikon Balzers Innova cathodic arc deposition system with a base pressure of less than $5 \times 10^{-2} \mathrm{~Pa}$. One $\mathrm{Ti}_{33} \mathrm{Al}_{67}$ and one $\mathrm{Zr}$ cathode were placed next to each other in the chamber to obtain different coating compositions along the dashed line in Figure 1a. Substrates were placed at three different positions S1-S3 as shown in Fig. 1b and the substrates were kept stationary during deposition (no rotation). The deposition was performed in a 3.5 Pa pure $\mathrm{N}_{2}$ atmosphere, at an evaporation current of $160 \mathrm{~A}$, a substrate temperature of $400{ }^{\circ} \mathrm{C}$, and a negative substrate bias of $30 \mathrm{~V}$. The deposition rate was approximately $170 \mathrm{~nm} / \mathrm{min}$.

Coating morphology and thickness were evaluated by scanning electron microscopy (SEM) of fractured cross-sectional samples using a LEO 1550 FEG-SEM. The chemical composition was determined by an Oxford X-Max electron dispersive x-ray spectroscopy (EDS) detector in the SEM, operated at an acceleration voltage of $20 \mathrm{kV}$. The detailed microstructure of as-deposited and annealed samples was studied by analytical (scanning) transmission electron microscopy (TEM/STEM) using either a FEI Technai G2 instrument operated at $200 \mathrm{kV}$ or a FEI Titan3 G2 60-300 dual aberration-corrected TEM/STEM instrument. Cross-sectional samples for TEM were prepared either by mechanical polishing followed by Ar ion etching to electron transparency using a Gatan precision ion polishing instrument 
or by focused ion beam milling using a $1540 \mathrm{EsB}$ cross beam instrument. X-ray diffractometry (XRD) using a Panalytical Cubix diffractometer in $\theta-2 \theta$ configuration and $\mathrm{Cu}-\mathrm{K} \alpha$ radiation was employed to establish the coating's phase content.

The hardness was evaluated by nanoindentation experiments on polished, tapered cross-sections using a UMIS 2000 system equipped with a Berkovich diamond tip and a load of $50 \mathrm{mN}$, resulting in indentation depths of 200-250 nm. The data was analyzed using the method of Oliver and Pharr [28] and the reported hardness is an average over 20 indents for each sample.

a.

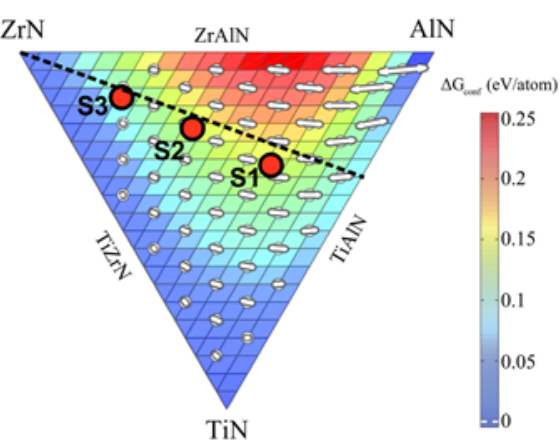

b.

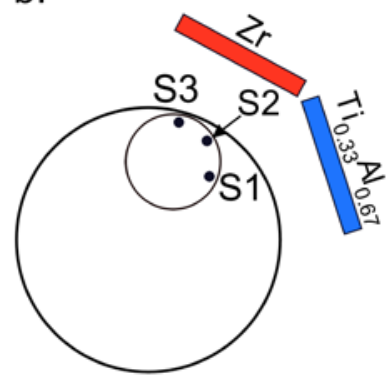

C.

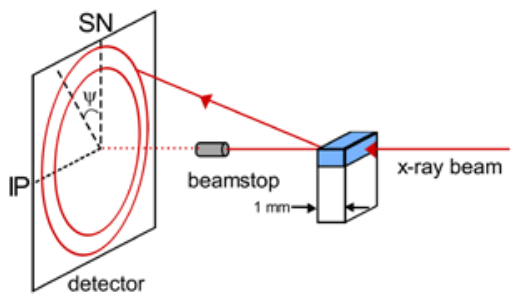

Figure 1: (a) Mixing free energy and tendency for spinodal decomposition for TiZrAIN showing samples S1, S2 and S3 [27], (b) Schematic illustration of the sample and cathode positions during deposition, and (c) illustration of the experimental setup during in situ WAXS annealing experiments. The surface normal (SN), the in-plane direction (IP) and the tilt angle $(\psi)$ are indicated in (b).

In situ wide-angle x-ray scattering (WAXS) experiments during annealing were performed at the highenergy materials science beamline P07 at Petra III, DESY, Hamburg. Data was recorded in transmission geometry as schematically shown in Figure $1 \mathrm{c}$ and for this purpose samples, about $1 \mathrm{~mm}$ thick, were prepared. The samples were placed in a Ta-holder inside a boron-nitride coated graphite tube heater positioned inside a vacuum chamber. The pressure was kept below $0.67 \mathrm{mPa}$ during the annealing experiment. The annealing sequence consisted of an initial step of constant heating rate to the maximum temperature, $T_{\max }$, followed by a $3 \mathrm{~h}$ holding time at $T_{\max }$ and further cooling to room temperature using the same rate as for heating. A Eurotherm controller was used to control the temperature, and heating and cooling rates to $20 \mathrm{~K} / \mathrm{min}$. All three samples were heated to $\mathrm{T}_{\max }=1100$ ${ }^{\circ} \mathrm{C}$ and for sample $\mathrm{S} 1$ an additional experiment was performed with $\mathrm{T}_{\max }=900^{\circ} \mathrm{C}$. The scattered $\mathrm{x}$-rays were detected by a two-dimensional $400 \times 400 \mathrm{~mm}^{2}$ PerkinElmer detector with a pixel size of $0.2 \times 0.2$ $\mathrm{mm}^{2}$. The wavelength was $0.168 \AA$ or $0.231 \AA \AA$ since the measurements were performed at two different occasions. In each case, the detector was positioned to collect the complete cubic 111 and 200 diffraction rings and the exact sample-to-detector distance was determined by a LaB $_{6}$ NIST standard powder. 
The two-dimensional data was integrated in $10^{\circ}$-wide bins centered at $\psi=0^{\circ}$ (along the surface normal, SN) and in a bin centered at $\psi=55^{\circ}$, to study the evolution of the cubic 200 and 111 peaks, respectively. The strain and stress was calculated using the $\sin ^{2} \psi$ method. The plane spacing (d) of 200 was determined from data integrated in $5^{\circ}$-wide bins. Due to the texture of the coatings, the 200 signal could only be collected for $\psi=\left[0^{\circ}: \pm 35^{\circ}\right]$ and $\psi=\left[ \pm 65^{\circ}: \pm 90^{\circ}\right]$. The $d$ vs $\sin ^{2} \psi$ dependence was assumed to be linear for the full $\psi=\left[0^{\circ}: \pm 90^{\circ}\right]$ range. The strain-free plane spacing was calculated at the invariant tilt angle $\psi^{*}$. Poisson's ratios and elastic moduli were taken from ab initio calculations [24] and are presented in Table 2.

Samples for microstructural investigations and hardness measurements were annealed using the same annealing chamber and annealing conditions as used during in situ experiments. Samples were annealed at $850^{\circ} \mathrm{C}$ (ramping to $850^{\circ} \mathrm{C}$ followed by immediate cooling to room temperature) and for 2 h at $1100^{\circ} \mathrm{C}$.

\section{Results and Discussion}

All three coatings exhibit a dense columnar structure with columnar widths of approximately $200-500$ $\mathrm{nm}$ as observed from the fractured cross sectional SEM micrographs in Figure 2a. The thickness is between 8 and $13 \mu \mathrm{m}$ (see Table 1). The chemical compositions of the samples as determined by EDS are S1: $\operatorname{Ti}_{0.31} Z_{0.24} \mathrm{Al}_{0.45} \mathrm{~N}, \mathrm{S2}: \mathrm{Ti}_{0.21} \mathrm{Zr}_{0.48} \mathrm{Al}_{0.31} \mathrm{~N}$ and S3: $\operatorname{Ti}_{0.13} Z_{0.69} \mathrm{Al}_{0.18} \mathrm{~N}$, also shown in Table 1. The variation in nitrogen-to-metal ratio between the samples as determined by EDS is small and is not further considered here.
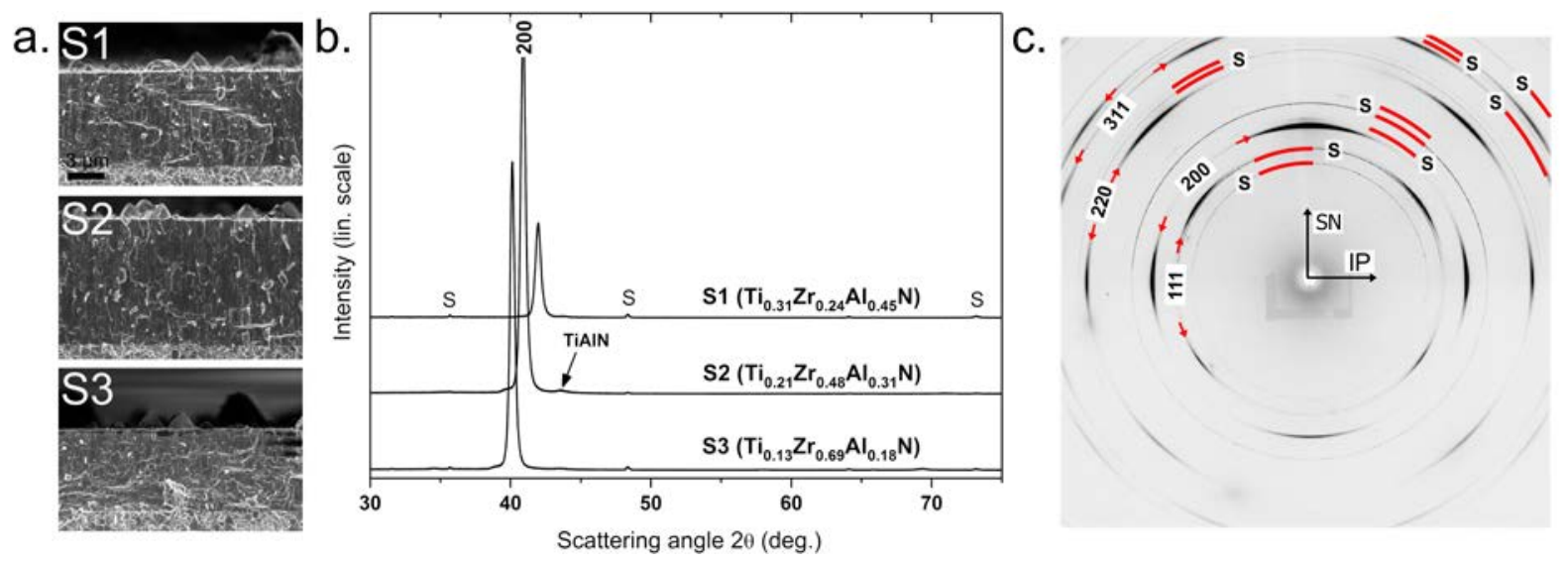

Figure 2: (a) Fractured cross sections and (b) $\theta-2 \theta$ diffractograms from the as-deposited coatings. (c) shows a two-dimensional diffraction pattern from the as-deposited $\mathrm{S} 1\left(\mathrm{Ti}_{0.31} \mathrm{Zr}_{0.24} \mathrm{Al} \mathrm{l}_{0.45} \mathrm{~N}\right)$ sample. Diffraction signal from the substrate is labelled S. The in-plane (IP) and surface normal (SN) are marked in (b). 
Table 1: Chemical composition determined by EDS and thickness of the as-deposited samples.

\begin{tabular}{ccccccc} 
Sample & Composition & $\begin{array}{c}\mathrm{Ti} \\
\text { at.\% }\end{array}$ & $\begin{array}{c}\mathrm{Zr} \\
\text { at.\% }\end{array}$ & $\begin{array}{c}\mathrm{Al} \\
\text { at.\% }\end{array}$ & $\begin{array}{c}\mathrm{N} \\
\text { at.\% }\end{array}$ & $\begin{array}{c}\text { Thickness } \\
(\mu \mathrm{m})\end{array}$ \\
\hline $\mathrm{S} 1$ & $\begin{array}{c}\mathrm{Ti}_{0.31} Z_{0.24} \mathrm{Al}_{0.45} \\
\mathrm{~N}\end{array}$ & 15.0 & 11.8 & 22.5 & 50.8 & 9.6 \\
$\mathrm{~S} 2$ & $\begin{array}{c}\mathrm{Ti}_{0.21} \mathrm{Zr}_{0.48} \mathrm{Al}_{0.31} \\
\mathrm{~N}\end{array}$ & 10.3 & 23.0 & 15.1 & 51.7 & 12.6 \\
$\mathrm{~S} 3$ & $\begin{array}{c}\mathrm{Ti}_{0.13} Z_{0.69} \mathrm{Al}_{0.18} \\
\mathrm{~N}\end{array}$ & 6.0 & 32.8 & 8.8 & 52.4 & 8.3
\end{tabular}

Figure $2 \mathrm{~b}$ shows $\theta-2 \theta$ diffractograms from the as-deposited $\mathrm{S} 1, \mathrm{~S} 2$ and $\mathrm{S} 3$ coatings. All three coatings reveal a 200 textured cubic structure. The weak diffraction peak centered at $43.5^{\circ}$ is assigned to small amounts of a TiAIN phase. Figure $2 \mathrm{c}$ shows a two-dimensional WAXS diffraction pattern from the $\mathrm{S} 1$ coating confirming the 200-textured cubic structure. Similar diffraction patterns were also collected for the other two samples. The weaker signal at the bottom half of the image is due to absorption of diffracted $x$-rays by the WC-Co substrate. The strain-free lattice parameter extracted from the 2D data is presented in Table 2. It agrees well with the calculated lattice parameter for a solid solution c-TiZrAIN phase [24]. Table 2 also shows the strain and stress of the as-deposited samples as deduced by the $\sin ^{2} \psi$ method. The stress is similar for S1 and S2 and slightly larger for S3. This is understood as an effect of S3 facing the Zr-cathode during growth which results in a larger amount of Zr-ions with a large mass and a high average charge state [29] and thus high ion energy arriving to the substrate, causing an increased amount of point defects. A similar trend was observed for TiAIN coatings [26] where the strain increased with increased Ti-content.

Figure 3 shows lineouts from $10^{\circ}$-wide bins centered at the $200\left(\psi=0^{\circ}\right)$ and $111\left(\psi=55^{\circ}\right)$ diffraction signal of S1 and S2 for different annealing times and temperatures. During heating to $1100{ }^{\circ} \mathrm{C}$, the cTiZrAIN 200 peak shifts to larger d-values due to thermal expansion and a change in chemical composition as discussed further below. In the temperature range of $900-1050^{\circ} \mathrm{C}$, both samples reveal additional broad peaks close to the 200 and 111 c-TiZrAIN diffraction peaks. For S1 (Fig. 3a), additional peaks appear both at smaller and higher $d$-values close to the c-TiZrAIN 200 (along the surface normal, $\left.\psi=0^{\circ}\right), 111\left(\psi=55^{\circ}\right)$ and $220\left(\psi=45^{\circ}\right.$, not shown) diffraction peaks. These peaks can be assigned to two additional cubic phases that form during the annealing stage, one with a smaller lattice parameter and one with a larger lattice parameter compared to the original c-TiZrAIN phase. For S2 (Fig. 3b), only the diffraction peaks attributed to a cubic phase with larger lattice parameter compared to the original cTiZrAIN is observed in the lineouts. The additional cubic phases grow with approximately the same amount of mosaicity as the original cubic c-TiZrAIN phase in both samples, as determined by the width of the peak in the $\psi$-direction. 
Table 2: Lattice parameter (a), strain and stress of the as-deposited samples. Shown is also the calculated values [24] for the lattice parameter (a), the elastic constants ( $E$ and $v$ ) and the Zener anisotropy ratio (A).

\begin{tabular}{cccccccc} 
Sample & $\begin{array}{c}\text { a (meas) } \\
(\AA)\end{array}$ & $\begin{array}{c}\text { Strain } \\
(\%)\end{array}$ & $\begin{array}{c}\text { Stress } \\
(\mathrm{GPa})\end{array}$ & $\begin{array}{c}\mathrm{a}(\text { calc) } \\
(\AA)\end{array}$ & $\begin{array}{c}\mathrm{E}(100) \text { (calc) } \\
(\mathrm{GPa})\end{array}$ & $v$ (calc) & $\mathrm{A}$ (calc) \\
\hline S1 & 4.29 & -0.71 & -2.6 & 4.285 & 370 & 0.216 & 1.3 \\
S2 & 4.40 & -0.73 & -2.7 & 4.400 & 369 & 0.238 & 1.0 \\
S3 & 4.47 & -0.83 & -3.5 & 4.480 & 420 & 0.243 & 0.80
\end{tabular}
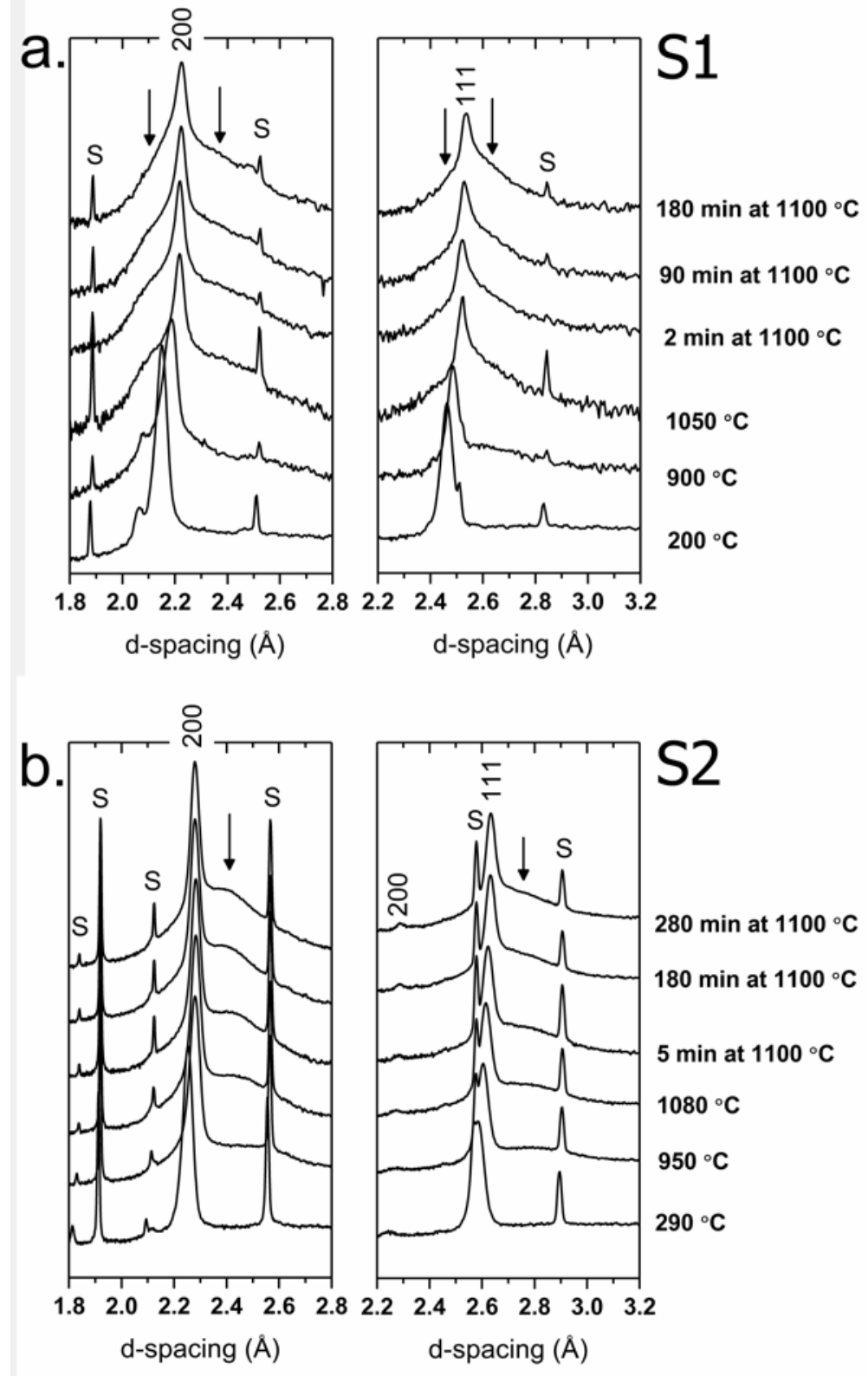

Figure 3: Lineouts integrated in a bin centered at $\psi=0^{\circ}$ (left) and in a bin centered at $\psi=55^{\circ}$ (right) for (a) S1 $\left(\mathrm{Ti}_{0.31} \mathrm{Zr}_{0.24} \mathrm{Al}_{0.45} \mathrm{~N}\right)$ and (b) S2 ( $\left.\mathrm{Ti}_{0.21} \mathrm{Zr}_{0.48} \mathrm{Al}_{0.31} \mathrm{~N}\right)$. 
The 200 diffraction peak of the cubic phase with a larger lattice parameter is centered at approximately 2.3-2.4 $\AA$, where the smaller value is found for the low Zr-content coating (S1). This is close to the expected position of $\mathrm{c}-\mathrm{ZrN}\left(\mathrm{d}_{\mathrm{ZrN} 200}=2.31 \AA\right.$ at $\left.1100{ }^{\circ} \mathrm{C}[30,31]\right)$ and thus we attribute this peak to a $\mathrm{Zr}$ rich c-(Ti)ZrN phase. The parenthesis indicates that small amounts of Ti might be present in this phase. The additional broad diffraction signal appearing at smaller d-values compared to the original c-TiZrAIN phase in S1 is likely a phase that is rich in Al or Ti. In addition, a peak from C-TiAIN is present in the asdeposited sample and observed at temperatures below $1050^{\circ} \mathrm{C}$. The amount of this phase is larger in S1 compared to S2. However, due to the small amount of c-TiAIN in the as-deposited sample, it is unlikely that this phase is the sole contribution to the shoulder and instead the shoulder contains additional contributions from Al- or Ti-rich phases that form during decomposition of c-TiZrAIN.

Figure 4 shows the change of the strain-free lattice parameter $\left(a^{*}\right)$ with annealing temperature and time of the main c-TiZrAIN phase (giving the highest diffracted intensity) relative to the value of the asdeposited coatings. The lattice parameter was determined from the 200 diffraction line. For all three coatings, the linear increase of a* between room temperature and approximately $600{ }^{\circ} \mathrm{C}$ is assigned to thermal expansion. For $\mathrm{S} 3$, the increase of the lattice parameter is linear up to $1100{ }^{\circ} \mathrm{C}$, thus no other contributions than thermal expansion appear to be affecting the lattice parameter in this case. Table 3 presents the lattice parameters after $3 \mathrm{~h}$ at $1100^{\circ} \mathrm{C}$ for the three samples. The small change in lattice parameter for S3 during annealing at $1100{ }^{\circ} \mathrm{C}$ indicates either a minor change in chemical composition of this phase or that annihilation of point defects (e.g. vacancies) affects the lattice parameter [32]. An earlier study revealed formation of AIN-rich precipitates during annealing at 1100 ${ }^{\circ} \mathrm{C}$ [27] for a coating with the same composition as S3. Thus, formation of small amounts of W-AIN in the coating is likely contributing to the change of lattice parameter. If all the $\mathrm{Al}$ is relocated from the cubic phase to w-AIN the lattice parameter of c-TiZrN would be $4.55 \AA$ A based on theoretical work [24]. Since the lattice parameter of S3 is smaller than this (see Table 3), the cubic phase still contains some Al. 


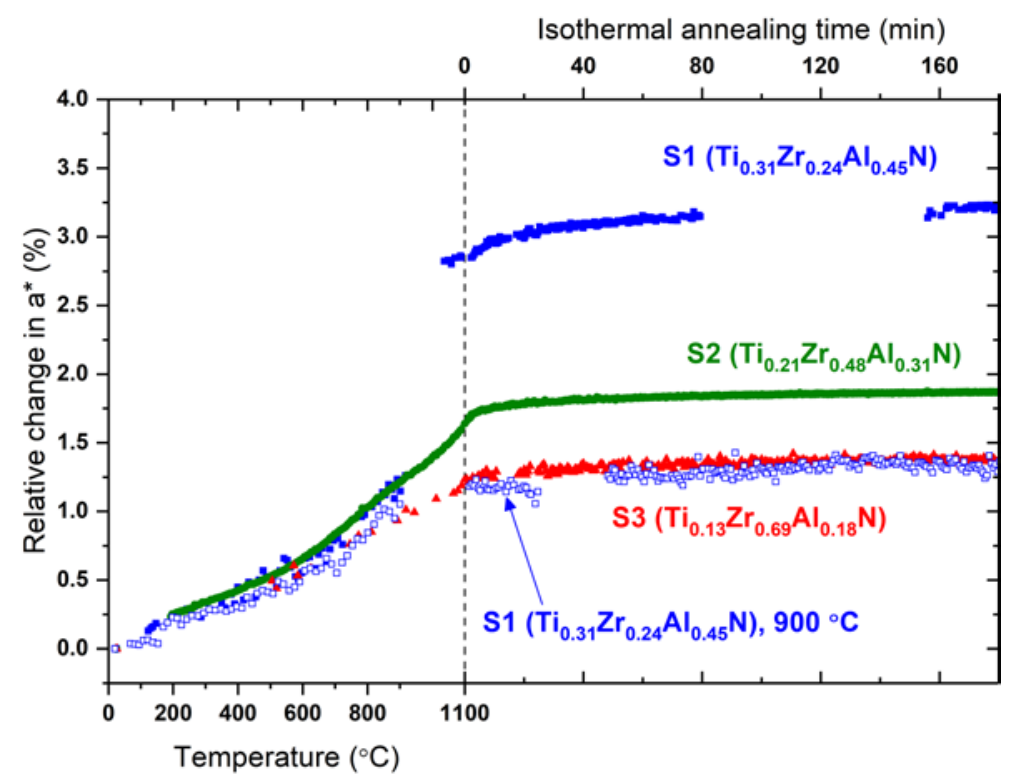

Figure 4: Relative change in un-strained lattice parameter as a function of annealing temperature and time. Filled symbols represents isothermal annealing at $1100^{\circ} \mathrm{C}$ and the open symbols the isothermal annealing of $\mathrm{Ti}_{0.31} \mathrm{Zr}_{0.24} \mathrm{Al}_{0.45} \mathrm{~N}$ at $900{ }^{\circ} \mathrm{C}$.

For $\mathrm{S} 1$ and $\mathrm{S} 2$, there is a change in expansion rate at $600{ }^{\circ} \mathrm{C}$, indicating that the lattice parameter is affected by the decomposition or by annihilation of defects (e.g. vacancies) as well as the thermal expansion. Between 900 and $1100{ }^{\circ} \mathrm{C}$, there is an additional change in expansion rate that is understood as depletion of Al from the cubic phase due to formation of w-AIN. For S1, this results in a drastic increase of the lattice parameter. The lattice parameter continues to increase slightly during isothermal annealing at $1100{ }^{\circ} \mathrm{C}$ suggesting that the chemical composition of the c-TiZrAIN phase continues to change throughout the $3 \mathrm{~h}$ long annealing. After the $3 \mathrm{~h}$ isothermal anneal, $\mathrm{S} 1$ shows the largest change of lattice parameter $\Delta \mathrm{a}$, see Table 3 . Some $\mathrm{Al}$ is still likely present in the c-TiZrAIN phase after annealing for $3 \mathrm{~h}$ considering that the lattice parameter is still increasing. For the same coating annealed at $900{ }^{\circ} \mathrm{C}$, there is no drastic increase of the lattice parameter, thus temperatures above 900 ${ }^{\circ} \mathrm{C}$ are required to cause nucleation of $\mathrm{W}$-AIN and a corresponding large change in chemical composition of the cubic phase. For S2, the lattice parameter is approximately constant during isothermal annealing, thus no or only small changes in chemical composition of the c-TiZrAIN phase occurs once $1100{ }^{\circ} \mathrm{C}$ has been reached. The main c-TiZrAIN phase may still contain some Al after annealing, similar to the case of the S3 sample. 
Table 3: Lattice parameter (a) and strain of samples annealed for $3 \mathrm{~h}$ at $1100{ }^{\circ} \mathrm{C}$ samples. The strain is measured during annealing and the lattice parameter is the room temperature value after annealing. The change in lattice parameter $(\Delta \mathrm{a})$ is the difference in value for the annealed and the as-deposited sample.

\begin{tabular}{cccc} 
Sample & $\begin{array}{c}\mathrm{a} \\
(\AA)\end{array}$ & $\begin{array}{c}\Delta \mathrm{a} \\
(\%)\end{array}$ & $\begin{array}{c}\text { Strain } \\
(\%)\end{array}$ \\
\hline S1 & 4.40 & 2.4 & -1.1 \\
S2 & 4.45 & 1.1 & -0.24 \\
S3 & 4.50 & 0.6 & -0.17
\end{tabular}

Figure 5 shows the strain of the main c-TiZrAIN phase (i.e. the phase giving the strongest diffraction signal) as a function of annealing temperature and time. An increase of the strain between room temperature and $600{ }^{\circ} \mathrm{C}$ of approximately $0.3 \%$, similar to the increase observed for the three samples, is estimated based on the difference in TEC of the substrate $\left(\sim 5 \times 10^{-6} \mathrm{~K}^{-1}[33]\right)$ and the coating $\left(9.48 \times 10^{-}\right.$ ${ }^{6} \mathrm{~K}^{-1}$ for $\mathrm{Ti}_{0.75} \mathrm{Al}_{0.25} \mathrm{~N}$ and $1.01 \times 10^{-5} \mathrm{~K}^{-1}$ for $\mathrm{Ti}_{0.50} \mathrm{Al}_{0.50} \mathrm{~N}$ [34]). At temperatures above $800{ }^{\circ} \mathrm{C}$ the strain decreases for S3 as is commonly observed for arc deposited coatings due to defect annihilation and grain growth $[26,35]$. In contrast, the strain increases at a faster rate between $600{ }^{\circ} \mathrm{C}$ and approximately $900^{\circ} \mathrm{C}$ for both S2 and S1.

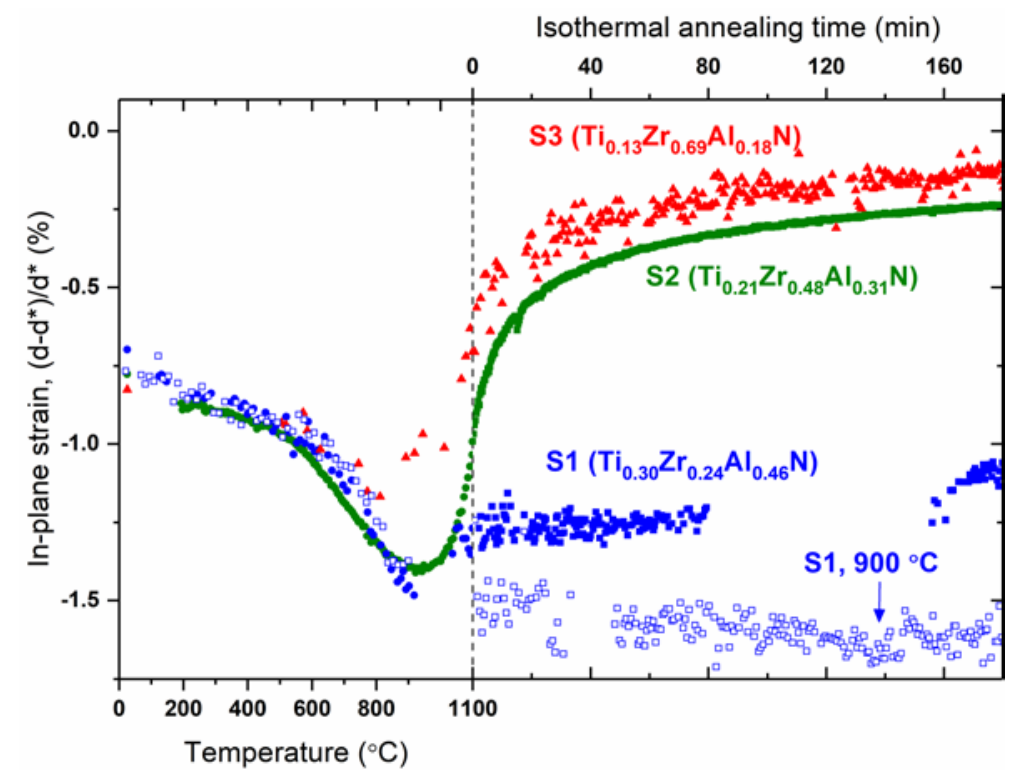

Figure 5: In-plane strain of the c-TiZrAIN phase as a function of annealing temperature and time. Filled symbols represents isothermal annealing at $1100{ }^{\circ} \mathrm{C}$ and the open symbols the isothermal annealing of S1 at $900{ }^{\circ} \mathrm{C}$.

Figure 6 shows elemental contrast STEM (Figure $6 a$ and $c$ ) and high-resolution HR-TEM (Figure $6 \mathrm{~b}$ and d) cross-sectional micrographs along the [011] zone axis of S1 (Figure 6a and b) and S2 (Figure 6c and d) annealed at $850^{\circ} \mathrm{C}$. Both coatings consist of large, columnar grains predominantly oriented with the 
cubic [100] direction along the surface normal (SN). During annealing at $850{ }^{\circ} \mathrm{C}$, phase separation occurs in both samples. For S1, Figure 6a shows Al-rich domains (dark contrast) elongated in the elastically compliant $\langle 100\rangle$ directions [24], throughout the coating thickness. Since the image is obtained along the [011] zone axis, the Al-rich domains are predominantly observed in the in-plane (IP) direction. Figure $6 \mathrm{~b}$ shows a HR-TEM micrograph of the same sample with the corresponding FFT, revealing a cubic structure, also across the Al-rich precipitates (indicated with arrows). Sample S2, Figure $6 \mathrm{c}$, shows large, bright contrast columnar grains together with dark contrast precipitates at column boundaries. The dark contrast precipitates observed in the column boundaries have a size of approximately $10 \mathrm{~nm}$ and are enriched in Al as confirmed by EDS. HR-TEM and FFT confirm that the largest of the precipitates are w-AIN (not shown). The diffraction signal from w-AIN cannot be observed in the 2D WAXS data and consequently the evolution of this phase cannot be determined from WAXS. One reason is that the signal from w-AIN overlaps with the broad diffraction signal from c-(Ti)ZrN. The broad peaks centered at $\sim 2.65 \AA$ and $\sim 2.35 \AA$ may contain diffraction signal from both c-(Ti)ZrN and w$\operatorname{AIN}\left(\mathrm{d}_{\mathrm{AINO02}}=2.51 \AA\right.$ and $\mathrm{d}_{\mathrm{AIN101}}=2.38 \AA$ at $\left.1100^{\circ} \mathrm{C}[36,37]\right)$. The broad diffraction peak centered at $\sim 2.35$ $\AA$ shifts to smaller values during heat treatment between $950{ }^{\circ} \mathrm{C}$ and $1080^{\circ} \mathrm{C}$ which may indicate an increasing amount of W-AIN in the coatings. Its peak position remains approximately constant during further annealing at $1100^{\circ} \mathrm{C}$.

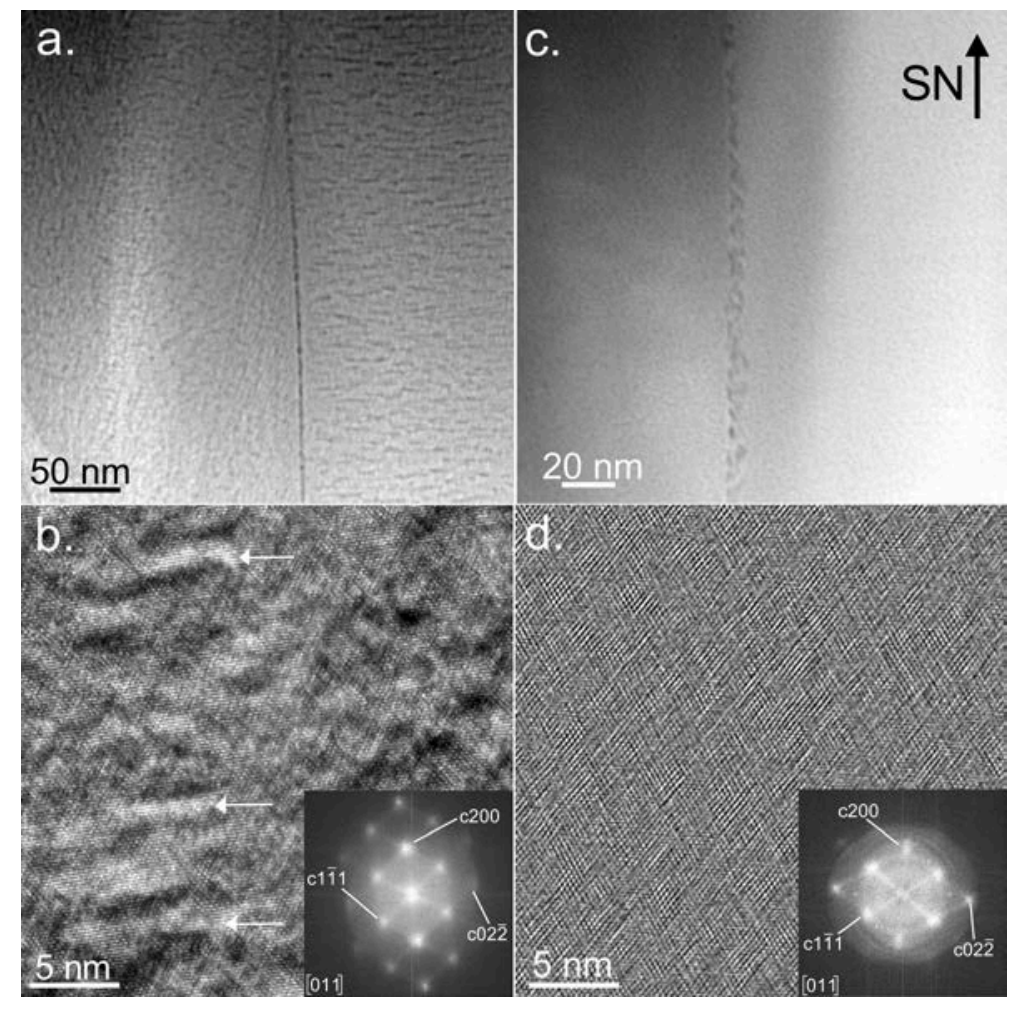

Figure 6: Elemental contrast STEM $(a, c)$ and HR-TEM $(b, d)$ cross-sectional micrographs from the S1 $\left(\operatorname{Ti}_{0.31} \mathrm{Zr}_{0.24} \mathrm{Al}_{0.45} \mathrm{~N}\right)(\mathrm{a}, \mathrm{b})$ and S2 $\left(\mathrm{Tii}_{0.21} \mathrm{Zr}_{0.48} \mathrm{Al}_{0.31} \mathrm{~N}\right)(\mathrm{c}, \mathrm{d})$ coatings annealed at $850{ }^{\circ} \mathrm{C}$ with no holding time. The arrows in (b) point at Al-rich precipitates and the surface normal (SN) is marked in (c). 
Within the columnar grains of S2 (Figure 6c), fine compositional modulations are observed. The HRTEM micrograph (Figure $6 \mathrm{~d}$ ) reveals a structure with small crystalline domains, 1-2 $\mathrm{nm}$, separated by regions that have a different structure or orientation. The crystalline domains have a cubic structure as revealed by the HR-TEM micrograph and the corresponding FFT. The size of the domains is on the same length scale as the compositional modulations observed in Figure 6c. Thus, separation into Alrich and Al-depleted domains has occurred during annealing in both samples. In S1, this results in a coherent, cubic structure while in S2, domains of different chemical composition form within the columnar grains and, in addition, w-AIN grains nucleate at column boundaries. The difference in elastic anisotropy between the samples [24], see Table 2, results in different shapes of the domains with cubic structure, where the domains are approximately equiaxed in the isotropic S2 sample.

The maximum strain was found to occur after annealing at $850{ }^{\circ} \mathrm{C}$. For TiAIN, a combination of experiments and phase field simulations revealed that only very small changes in strain of the c-TiAIN phase is expected upon spinodal decomposition [26], as long as the formed domains of different chemical composition are coherent. The formation of w-AIN, however, can increase the compressive strains in the c-TiAIN phase $[38,39]$. Thus, formation of small w-AIN grains is likely the reason for the increased strain in $\mathrm{S} 2$ below $900^{\circ} \mathrm{C}$. Also, formation of domains with a different structure or orientation within the columns can contribute to the compressive strain in S2. For S1 annealed at $900{ }^{\circ} \mathrm{C}$, most of the $\mathrm{Al}$ is retained within the cubic structure as revealed by the small change in lattice parameter (Figure 4). The high strain in this sample (Figure 5) confirms that it is the structure of the cubic phase that is causing the high compressive strain. Thus, the more complex phase evolution in the quaternary TizrAIN alloy compared to TiAIN, where also formation of Ti- and Zr-rich phases takes place, results in compressive strain.

Figure 7 shows elemental contrast STEM (Figure 7a and d), high-resolution HR-TEM (Figure 7b and e) and elemental contrast, high-resolution HR-STEM micrographs (Figure 7c and f) of S1 (Figure 7a-c) and S2 (Figure $7 \mathrm{~d}-\mathrm{f}$ ) annealed for $2 \mathrm{~h}$ at $1100{ }^{\circ} \mathrm{C}$. For S1, dark contrast, almost equiaxed Al-rich grains (indicated with arrows) have formed. One embedded Al-rich grain is imaged in Figure 7b. A FFT of this grain displays a hexagonal structure, indicating that such Al-rich grains are w-AIN. The inserted FFT is obtained from the full image and reveal the existence of both cubic and wurtzite phases. The w-AIN grains form with their $<0001>$ directions parallel to the cubic $<001>$ directions. Yalamanchili et al. [25] calculated the interfacial energy for different interface structures for c-TiN, c-ZrN and w-AIN and found that c-(110)[001] || w-(10-10)[0001] is one of the favored interface structures for c-ZrN and w-AIN. 


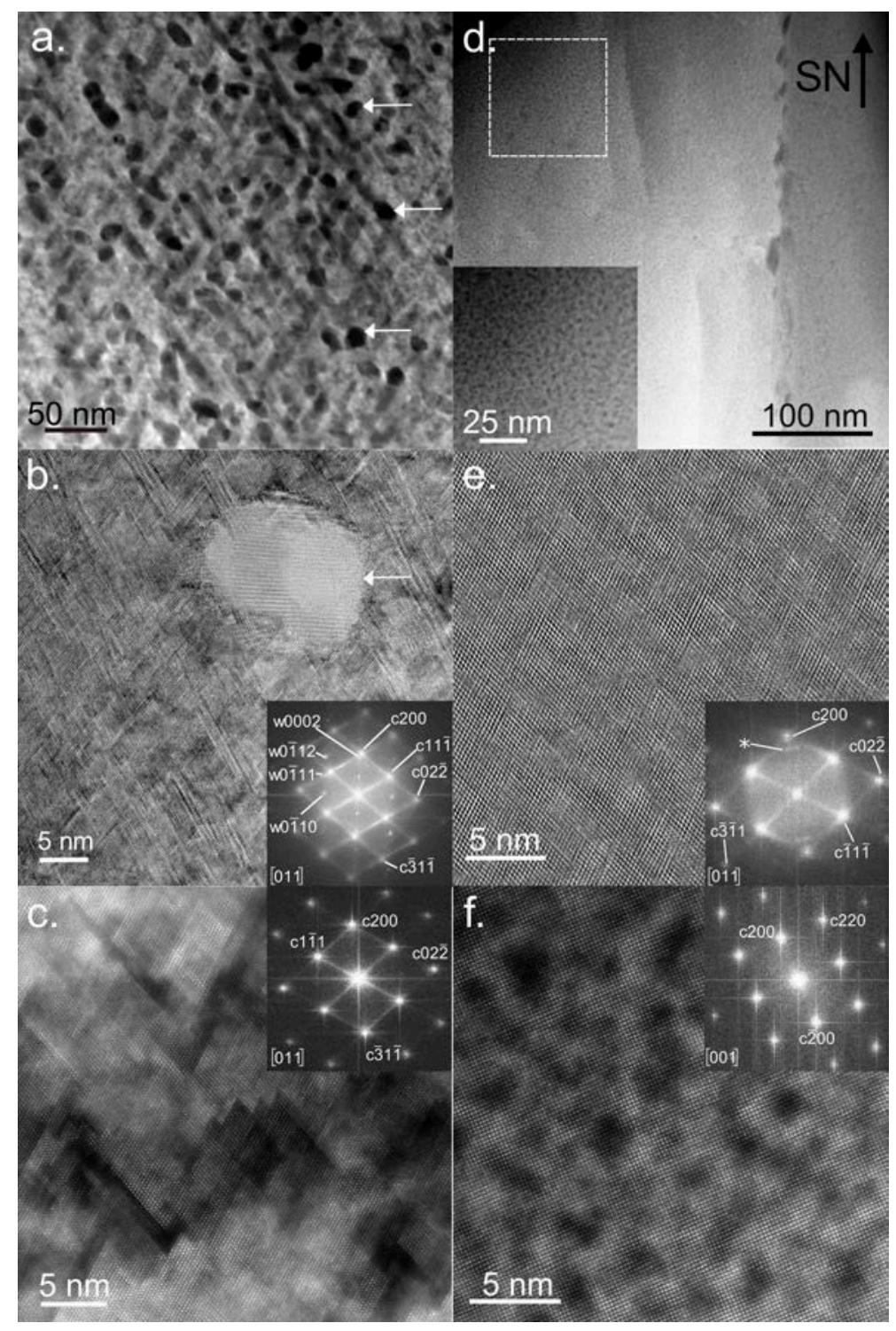

Figure 7: Elemental contrast STEM (a,d), HR-TEM (b,e) and elemental contrast HR-STEM (c,f) cross-sectional micrographs from the S1 ( $\left.\operatorname{Ti}_{0.31} \mathrm{Zr}_{0.24} \mathrm{Al}_{0.45} \mathrm{~N}\right)(\mathrm{a}-\mathrm{c})$ and $\mathrm{S} 2\left(\mathrm{Ti}_{0.21} \mathrm{Zr}_{0.48} \mathrm{Al}_{0.31} \mathrm{~N}\right)(\mathrm{d}-\mathrm{f})$ coatings annealed for $2 \mathrm{~h}$ at $1100^{\circ} \mathrm{C}$. The arrows in (a,b) point at Al-rich precipitates and the surface normal (SN) is marked in (d).

This relation has also been observed experimentally [20]. Thus, the w-AIN grains grow such that the interfacial energy is minimized. The structure surrounding the W-AIN grains is cubic as revealed by the HR-TEM micrographs in Figure 7b-c. The elemental contrast HR micrograph in Figure 7c reveals varying contrast within the cubic structure corresponding to differences in $\mathrm{Ti}$ - and $\mathrm{Zr}$-content. The cubic structure has a high density of dislocations and stacking faults where the dislocations are mainly located on (111) planes with their Burgers vector in the [111] direction as determined by Burgers circuits around the observed dislocations. These are interpreted as Frank partial dislocations outlining stacking faults in the structure. Thus, depletion of Al from the cubic phase and the nucleation of w-AIN grains are associated with a change in orientation of the interfaces between cubic domains, from (100) 
interfaces to (111) interfaces. It has been observed that during spinodal decomposition of Cu-Ni-Fe alloys, a change in orientation, from (100) coherent interfaces to (110) oriented interfaces [40, 41], caused by concentration of dislocations to the interfaces between phases, lowers the interfacial energy since the Burgers vector of the dislocations is located in this plane. Similarly, in the TiZrAIN coatings, the change of interface orientation to contain the Burgers vector of the dislocations can lower the interfacial energy and thus be favorable. There are additional compositional modulations within the cubic domains aligned along $<111>$ directions as observed in Figure 7c. The large variation in composition within the cubic phase and the local strain resulting from dislocations result in broad diffraction peaks that appear during annealing (Figure 3).

In S2, the Al-rich precipitates have grown during annealing at $1100^{\circ} \mathrm{C}$ and they are still mainly located at column boundaries as observed in Figure $7 \mathrm{~d}$. There are still fine-scale compositional modulations within the cubic, columnar grains as revealed by the higher magnification STEM insert in Figure $7 \mathrm{~d}$. The elemental contrast HR-STEM micrograph recorded along the [001] zone axis in Figure $7 f$ show cubic structure domains that are 3-4 $\mathrm{nm}$ in size with varying contrast, corresponding to variations in composition between the domains. The HR-TEM micrograph in Figure 7e, recorded along the [011] zone axis, reveal that some domains have either a different orientation or a different structure than the major part of the column interior. In the inserted FFT (Figure 7e), there are weak spots (marked with ${ }^{*}$ ) along the cubic [100] direction that can be assigned to either cubic (111) or wurtzite (0002) planes. In contrast to S1, larger W-AIN grains are only found at the column boundaries and not within the columns for this sample.

Above $900{ }^{\circ} \mathrm{C}$ the growth of w-AIN grains at column boundaries result in strain relaxation of the c$\operatorname{TiZr}(\mathrm{Al}) \mathrm{N}$ phase (Figure 5), similar to the case of TiAIN where the strains relaxes when the w-AlN grains increase in size [26]. In contrast, relaxation does not take place in $\mathrm{S} 1$ above $900^{\circ} \mathrm{C}$. Instead, the stable and dense dislocation structure and nucleation of W-AIN within the cubic structure cause the coating to remain in a compressive stress state. The stable dislocation structure is caused by the sessile partial dislocations with a [111] oriented Burgers vector. Such dislocations require other mechanisms to move then glide, such as climb, which likely contribute to the slow strain relaxation throughout the $3 \mathrm{~h}$ long annealing. Comparing the strain evolution of S1 and S2 during growth of w-AIN between $900 \mathrm{C}$ and $1100^{\circ} \mathrm{C}$ it is obvious that the nucleation site for w-AIN is important for the strain evolution. Nucleation and growth of w-AIN in the column boundaries in S2 results in strain relaxation of the cubic phase, while nucleation of w-AIN within the cubic grains results in retained compressive strains. This is understood by column boundaries having lower density then the interior of the columns. This allows growth of the larger molar volume w-AIN phase without compressing the cubic, columnar grains. In contrast, the formation of w-AIN within the cubic, columnar grains likely results in an internal 
compressive stress. The compressive stress of S2 and S3 after $3 \mathrm{~h}$ at $1100{ }^{\circ} \mathrm{C}$ is mainly due to the difference in thermal expansion between substrate and coating. The strain determined at room temperature after $3 \mathrm{~h}$ at $1100{ }^{\circ} \mathrm{C}$ is $-0.05 \%$ for $\mathrm{S} 3$, corresponding to an approximate compressive stress of $0.2 \mathrm{GPa}$ (using the same elastic constants as for the as-deposited coating).

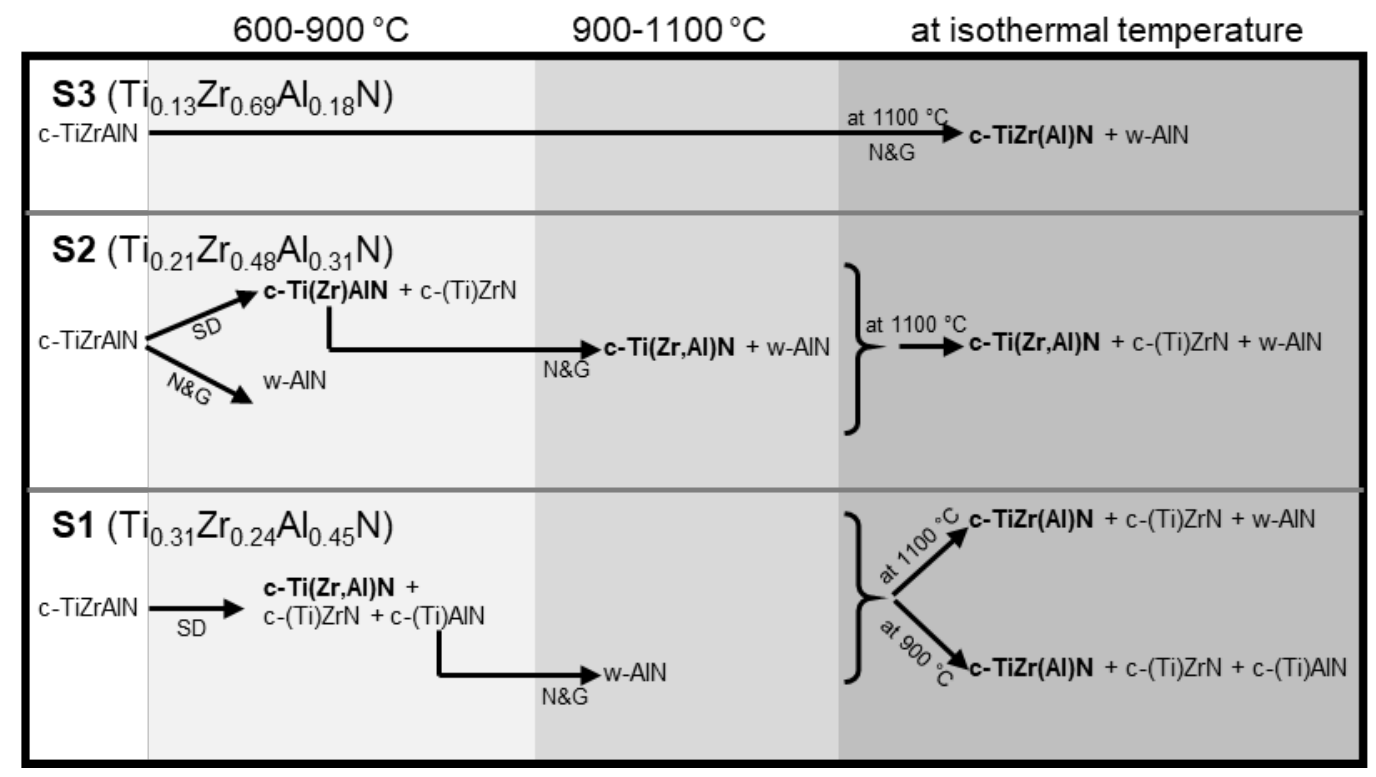

Figure 8: Decomposition routes of the three coatings showing phase transformation by spinodal decomposition (SD) and nucleation and growth (N\&G) mechanisms. Parenthesis indicates elements that exist in minor amounts and phases in bold text are the main phases.

Figure 8 summarizes the decomposition routes of the three studied samples. S3 $\left(\operatorname{Ti}_{0.13} \mathrm{Zr}_{0.69} \mathrm{Al}_{0.18} \mathrm{~N}\right.$ ) decomposes by nucleation and growth (N\&G) into an Al-depleted c-TiZr(AI)N phase and w-AIN in agreement with theoretical predictions [27]. In $\mathrm{S} 2\left(\mathrm{Ti}_{0.21} \mathrm{Zr}_{0.48} \mathrm{Al}_{0.31} \mathrm{~N}\right)$, theoretical work found a small driving force for spinodal decomposition (SD). Here, we find two co-occurring mechanisms for decomposition. Spinodal decomposition of the c-TiZrAIN phase results in domains enriched in Ti or Zr, while there is simultaneous growth of w-AIN mainly in the column boundaries of the coating. This is similar to what previously has been observed for TiCrAIN [12]. After $3 \mathrm{~h}$ at $1100^{\circ} \mathrm{C}$ the final phases are w-AIN, a Zr-rich c-TiZrN phase, and the main c-TiZr(AI)N phase. The driving force for spinodal decomposition is the highest for $\mathrm{S} 1\left(\mathrm{Ti}_{0.31} \mathrm{Zr}_{0.24} \mathrm{Al}_{0.45} \mathrm{~N}\right)$ [27] and below $900{ }^{\circ} \mathrm{C}$ only spinodal decomposition is observed, resulting in cubic domains enriched in Al and Zr. Nucleation and growth of W-AIN occurs subsequent to the spinodal decomposition at temperatures above $900{ }^{\circ} \mathrm{C}$. The w-AIN phase forms from c-AIN-rich domains within the cubic grains, resulting in well-dispersed w-AIN grains throughout the coating. The continuous change in lattice parameter of the main c-TiZrAIN phase during isothermal annealing suggests that its chemical composition is still changing at $1100{ }^{\circ} \mathrm{C}$. During 
isothermal annealing at $900{ }^{\circ} \mathrm{C}$, the changes in lattice parameter are relatively small, thus most of the Al is still contained within the cubic phase, even after $3 \mathrm{~h}$ of annealing.

Figure 9 shows the hardness evolution during annealing. The hardness decreases during annealing for S3 due to strain relaxation and nucleation and growth of w-AIN. In contrast, the hardness is constant for S2 to annealing temperatures of $1100 \mathrm{C}^{\circ}$ (hold time of $25 \mathrm{~min}$ ) despite the strain relaxation that takes place above $900{ }^{\circ} \mathrm{C}$. This is assigned to the formation of $\mathrm{nm}$-sized domains within the cubic structure, resulting in age hardening similar to the case of TiAIN [42]. For S1, the hardness increases slightly during annealing at $850^{\circ} \mathrm{C}$ (no hold) due to the formation of elongated, coherent AIN-rich cubic domains. During annealing at $1100{ }^{\circ} \mathrm{C}$ the hardness decreases slightly but remains high (31 GPa) even after $2 \mathrm{~h}$ at $1100^{\circ} \mathrm{C}$ as a result of the dislocation-dense structure formed and the high compressive strain.

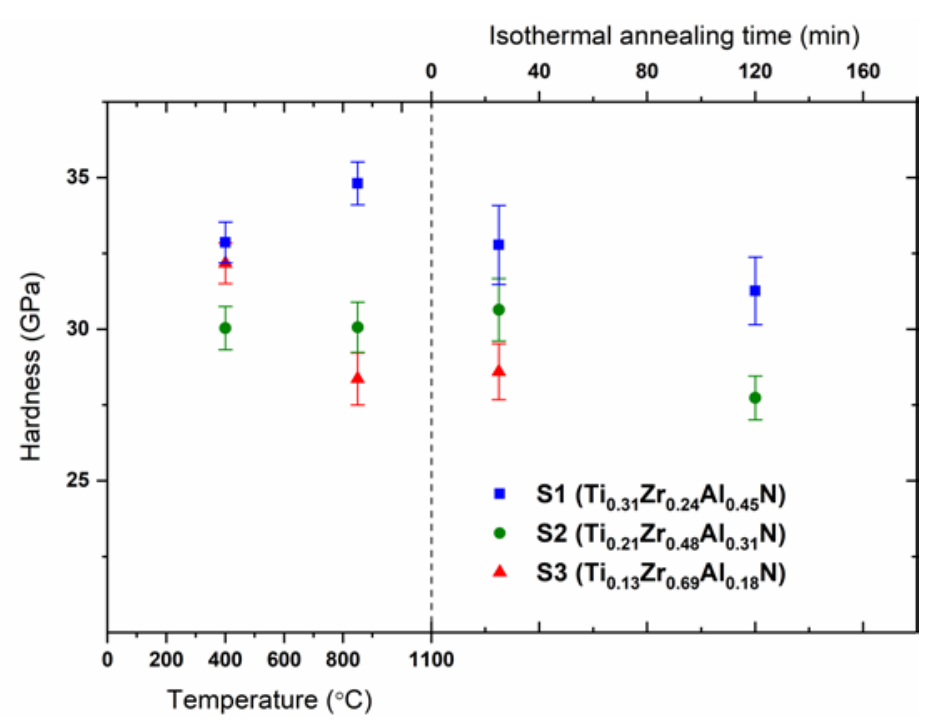

Figure 9: Hardness of the samples as a function of annealing temperature and time. 


\section{Conclusions}

The decomposition route of c-TiZrAIN changes from nucleation and growth of w-AIN to spinodal decomposition when the $\mathrm{Zr}$-content in the coating decreases and the Al-content increases. Spinodal decomposition during annealing results in cubic domains enriched in $\mathrm{Zr}$ or $\mathrm{Ti} / \mathrm{Al}$ and the formed microstructure depends on coating composition. In $\mathrm{Ti}_{0.31} \mathrm{Zr}_{0.24} \mathrm{Al}_{0.45} \mathrm{~N}$, spinodal decomposition below $900{ }^{\circ} \mathrm{C}$ results in cubic domains elongated in $\left.<100\right\rangle$ directions. During further annealing, there is a change in orientation of the interfaces between the domains, resulting in (111) oriented semi-coherent interfaces. The dislocation-dense structure formed and additional nucleation of w-AIN within the columnar grains result in high compressive strain of the cubic phase during isothermal annealing at $1100{ }^{\circ} \mathrm{C}$. In $\mathrm{Ti}_{0.21} \mathrm{Zr}_{0.48} \mathrm{Al}_{0.31} \mathrm{~N}$, loss of coherency occurs at lower temperatures and above $900{ }^{\circ} \mathrm{C}$ recrystallization and grain growth result in a decreased strain.

\section{Acknowledgements}

This study was performed in the framework of the competence center FunMat-II that is financially supported by Vinnova (grant no 2016-05156). The Swedish Government Strategic Research Area (SFO Mat LiU, grant no 2009 00971), and Swedish Research council (grant no 2017-03813) are acknowledged for financial support. The use of PETRA III was enabled through support by the Röntgen-Ångström Cluster frame grants (grant no VR 2011-6505 and VR 2017-06701). The authors also thank MSc Tun-Wei Hsu for assistance with hardness measurements. 


\section{References}

[1] H. Lind, R. Forsén, B. Alling, N. Ghafoor, F. Tasnádi, M.P. Johansson, I.A. Abrikosov, M. Odén, Improving thermal stability of hard coating films via a concept of multicomponent alloying, Appl. Phys. Lett. 99 (2011) 091903.

[2] A. Knutsson, I.C. Schramm, K. Asp Grönhagen, F. Mücklich, M. Odén, Surface directed spinodal decomposition at TiAIN/TiN interfaces, J. Appl. Phys. 113(11) (2013) 114305.

[3] P.H. Mayrhofer, A. Hörling, L. Karlsson, C. Mitterer, L. Hultman, Self-organized nanostructures in the Ti-Al-N system, Appl. Phys. Lett. 83(10) (2003) 2049-2051.

[4] A. Knutsson, J. Ullbrand, L. Rogström, N. Norrby, L.J.S. Johnson, L. Hultman, J. Almer, M.P.J. Jöesaar, B. Jansson, M. Odén, Microstructure evolution during the isostructural decomposition of TiAIN - A combined in-situ small angle x-ray scattering and phase field study, J. Appl. Phys. 113 (2013) 213518.

[5] R. Forsen, M. Johansson, M. Oden, N. Ghafoor, Decomposition and phase transformation in TiCrAIN thin coatings, J. Vac. Sci. Technol. A 30(6) (2012) 061506-8.

[6] L. Chen, D. Holec, Y. Du, P.H. Mayrhofer, Influence of Zr on structure, mechanical and thermal properties of Ti-Al-N, Thin Solid Films 519 (2011) 5503-5510.

[7] L. Chen, L. He, Y. Xu, L. Zhou, F. Pei, Y. Du, Influence of ZrN on oxidation resistance of Ti-Al-N coating, Surf. Coat. Technol. 244 (2014) 87-91.

[8] R. Rachbauer, D. Holec, M. Lattemann, L. Hultman, P.H. Mayrhofer, Electronic origin of structure and mechanical properties in $\mathrm{Y}$ and Nb alloyed Ti-Al-N thin films, Int. J. Mat. Res. 102(6) (2011) 735742.

[9] M. Mikula, D. Plašienka, D.G. Sangiovanni, M. Sahul, T. Roch, M. Truchlý, M. Gregor, L.u. Čaplovič, A. Plecenik, P. Kúš, Toughness enhancement in highly NbN-alloyed Ti-Al-N hard coatings, Acta Mater. 121 (2016) 59-67.

[10] F. Tasnádi, L. Rogström, J. Zhu, F. Wang, T.W. Hsu, H. Lind, I.A. Abrikosov, M.P. Johansson-Jõesaar, M. Odén, High temperature thermodynamics of spinodal decomposition in arc deposited $\mathrm{Ti}_{x} \mathrm{Nb}_{\mathrm{y}} \mathrm{Al}_{z} \mathrm{~N}$ coatings, Mater. Des. 150 (2018) 165-170.

[11] Y.H. Chen, J.J. Roa, C.H. Yu, M.P. Johansson-Jõesaar, J.M. Andersson, M.J. Anglada, M. Odén, L. Rogström, Enhanced thermal stability and fracture toughness of TiAIN coatings by $\mathrm{Cr}, \mathrm{Nb}$ and $\mathrm{V}$ alloying, Surf. Coat. Technol. 342 (2018) 85-93.

[12] R. Forsén, M.P. Johansson, M. Odén, N. Ghafoor, Effects of Ti alloying of AlCrN coatings on thermal stability and oxidation resistance, Thin Solid Films 534(0) (2013) 394-402.

[13] Y.H. Chen, L. Rogström, D. Ostach, N. Ghafoor, M.P. Johansson-Jõesaar, N. Schell, J. Birch, M. Odén, Effects of decomposition route and microstructure on h-AIN formation rate in TiCrAIN alloys, J. Alloys Compd. 691 (2017) 1024-1032.

[14] S.H. Sheng, R.F. Zhang, S. Veprek, Phase stabilities and thermal decomposition in the $\mathrm{Zr}_{1-x} \mathrm{Al}{ }_{x} \mathrm{~N}$ system studied by ab initio calculation and thermodynamic modeling, Acta Mater. 56 (2008) 968-976.

[15] D. Holec, R. Rachbauer, L. Chen, L. Wang, D. Luef, P.H. Mayrhofer, Phase stability and alloy-related trends in Ti-Al-N, Zr-Al-N and Hf-Al-N systems from first principles, Surf. Coat. Technol. 206(7) (2011) 1698-1704.

[16] Y. Makino, M. Mori, S. Miyake, K. Saito, K. Asami, Characterization of Zr-Al-N films synthesized by a magnetron sputtering method, Surf. Coat. Technol. 193 (2005) 219-222.

[17] L. Rogström, M.P. Johansson, N. Ghafoor, L. Hultman, M. Oden, Influence of chemical composition and deposition conditions on microstructure evolution during annealing of arc evaporated ZrAIN thin films, J. Vac. Sci. Technol. A 30(3) (2012) 031504.

[18] L. Rogström, M. Ahlgren, J. Almer, L. Hultman, M. Odén, Phase transformations in nanocomposite ZrAIN thin films during annealing, J. Mater. Res. 27(13) (2012) 1716-1724.

[19] P.H. Mayrhofer, D. Sonnleitner, M. Bartosik, D. Holec, Structural and mechanical evolution of reactively and non-reactively sputtered $\mathrm{Zr}-\mathrm{Al}-\mathrm{N}$ thin films during annealing, Surf. Coat. Technol. 244(0) (2014) 52-56. 
[20] N. Ghafoor, L.J.S. Johnson, D.O. Klenov, J. Demeulemeester, P. Desjardins, I. Petrov, L. Hultman, M. Oden, Nanolabyrinthine ZrAIN thin films by self-organization of interwoven single-crystal cubic and hexagonal phases, APL Mater. 1(2) (2013) 022105-6.

[21] I.A. Saladukhin, G. Abadias, A. Michel, S.V. Zlotski, V.V. Uglov, G.N. Tolmachova, S.N. Dub, Influence of Al content on the phase formation, growth stress and mechanical properties of TiZrAIN coatings, Thin Solid Films 538(0) (2013) 32-41.

[22] G. Abadias, I.A. Saladukhin, V.V. Uglov, S.V. Zlotski, D. Eyidi, Thermal stability and oxidation behavior of quaternary TiZrAIN magnetron sputtered thin films: Influence of the pristine microstructure, Surf. Coat. Technol. 237 (2013) 187-195.

[23] D.G. Sangiovanni, L. Hultman, V. Chirita, Supertoughening in B1 transition metal nitride alloys by increased valence electron concentration, Acta Mater. 59(5) (2011) 2121-2134.

[24] F. Wang, D. Holec, M. Odén, F. Mücklich, I.A. Abrikosov, F. Tasnádi, Systematic ab initio investigation of the elastic modulus in quaternary transition metal nitride alloys and their coherent multilayers, Acta Mater. 127 (2017) 124-132.

[25] K. Yalamanchili, F. Wang, H. Aboulfadl, J. Barrirero, L. Rogström, E. Jiménez-Pique, F. Mücklich, F. Tasnadi, M. Odén, N. Ghafoor, Growth and thermal stability of TiN/ZrAIN: Effect of internal interfaces, Acta Mater. 121 (2016) 396-406.

[26] L. Rogström, J. Ullbrand, J. Almer, L. Hultman, B. Jansson, M. Odén, Strain evolution during spinodal decomposition of TiAIN thin films, Thin Solid Films 520 (2012) 5542-5549.

[27] H. Lind, R. Pilemalm, L. Rogström, F. Tasnadi, N. Ghafoor, R. Forsén, L.J. S. Johnson, M.P. Johansson-Jöesaar, M. Odén, I.A. Abrikosov, High temperature phase decomposition in $\mathrm{Ti}_{x} \mathrm{Zr}_{y} \mathrm{Al}_{z} \mathrm{~N}, \mathrm{AIP}$ Adv. 4(12) (2014) 127147.

[28] W.C. Oliver, G.M. Pharr, An improved technique for determining hardness and elastic modulus using load and displacement sensing indentation experiments, J. Mater. Res. 7(6) (1992) 1564-1583.

[29] A. Anders, Ion charge state distributions of vacuum arc plasmas: The origin of species, Phys. Rev. E 55(1) (1997) 969.

[30] fcc-ZrN, PDF No. 25-1133, JCPDS - International Centre for Diffraction Data, 1998.

[31] L.E. Toth, Transition Metal Carbides and Nitrides, Academic Press, New York and London, 1971.

[32] I.C. Schramm, M.P. Johansson Jõesaar, J. Jensen, F. Mücklich, M. Odén, Impact of nitrogen vacancies on the high temperature behavior of $\left(\mathrm{Ti}_{1-\mathrm{x}} \mathrm{Al}_{\mathrm{x}}\right) \mathrm{N}_{\mathrm{y}}$ alloys, Acta Mater. 119 (2016) 218-228.

[33] B. Uhrenius, Evaluation of molar volumes in the Co-W-C system and calculation of volume fractions of phases in cemented carbides, Int. J. Refr. Metal. Hard Mat. 12 (1994) 121-127.

[34] N. Shulumba, O. Hellman, L. Rogström, Z. Raza, F. Tasnádi, I.A. Abrikosov, M. Odén, Temperaturedependent elastic properties of $\mathrm{Ti}_{1-x} \mathrm{Al}_{x} \mathrm{~N}$ alloys, Appl. Phys. Lett. 107(23) (2015) 231901.

[35] L. Karlsson, A. Hörling, M.P. Johansson, L. Hultman, G. Ramanath, The influence of thermal annealing on residual stresses and mechanical properties of arc-evaporated $\mathrm{TiC}_{x} \mathrm{~N}_{1-\mathrm{x}}(\mathrm{x}=0,0.15$ and 0.45) thin films Acta Mater. 50 (2002) 5103-5114.

[36] w-AIN, PDF No. 25-1133, JCPDS - International Centre for Diffraction Data, 1998.

[37] G.A. Slack, S.F. Bartram, Thermal expansion of some diamondlike crystals, J. Appl. Phys. 46(1) (1975) 89-98.

[38] C. Wustefeld, D. Rafaja, M. Dopita, M. Motylenko, C. Baehtz, C. Michotte, M. Kathrein, Decomposition kinetics in $\mathrm{Ti}_{1-x} \mathrm{Al}_{x} \mathrm{~N}$ coatings as studied by in-situ $\mathrm{X}$-ray diffraction during annealing, Surf. Coat. Technol. 206(7) (2011) 1727-1734.

[39] R. Rachbauer, S. Massl, E. Stergar, D. Holec, D. Kiener, J. Keckes, J. Patscheider, M. Stiefel, H. Leitner, P.H. Mayrhofer, Decomposition pathways in age hardening of Ti-Al-N films, J. Appl. Phys. 110 (2011) 023515.

[40] E.P. Butler, G. Thomas, Structure and properties of spinodally decomposed Cu-Ni-Fe alloys, Acta Metal. 18 (1970) 347-365.

[41] R.J. Livak, G. Thomas, Loss of coherency in spinodally decomposed Cu-Ni-Fe alloys, Acta Metal. 22 (1974) 589-599.

[42] A. Knutsson, M.P. Johansson, L. Karlsson, M. Oden, Thermally enhanced mechanical properties of arc evaporated $\mathrm{Ti}_{0.34} \mathrm{Al}_{0.66} \mathrm{~N} / \mathrm{TiN}$ multilayer coatings, J. Appl. Phys. 108(4) (2010) 044312-7. 